
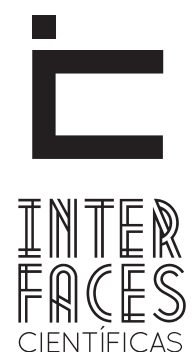

EDUCAÇÃO

\title{
EDUCAÇ̃̃O DOS PESCADORES: SABERES FORMAIS NA EDUCAÇ̃̃O DE JOVENS E ADULTOS VERSUS SABERES TRADICIONAIS NAS COMUNIDADES
}

Vanda Maria Campos Salmeron Dantas ${ }^{i}$

\section{RESUMO}

Diante dos aspectos históricos e culturais que integram o indivíduo ao meio social, é relevante um estudo que possibilite analisar o papel da escola e a formação do professor que leciona no programa Educação de Jovens e Adultos - EJA, e no Ensino Médio, no sentido de investigar se os saberes tradicionais da população ribeirinha estão presentes no currículo escolar, no projeto político pedagógico da escola. É primordial que as informações sobre as habilidades e competências das comunidades ribeirinhas trabalhadas na escola envolvam reflexão, tanto individual como coletiva, pois é esse exercício que permitirá a homens e mulheres se reconhecerem como sujeitos do seu contexto social e cultural, os quais, com essa certeza, poderão ser capazes de construir relações mais saudáveis e positivas no ambiente em que estão inseridos. Frente a esse contexto, é que está sendo desenvolvida uma pesquisa com a finalidade de conhecer o espaço es- colar e seus atores sociais a fim de possibilitar a compreensão do que limita esse espaço, no sentido de integrar os saberes das comunidades e analisar essa complexidade de saberes de mulheres e homens que constroem conhecimentos e os repassam de geração a geração. Para tanto, será enfatizado o papel da EJA e do Ensino Médio através dos professores que trabalham na região, na perspectiva de uma prática de transformação da ação pedagógica. Analisar-se-á, ainda, de que forma ocorre o processo de aprendizagem no espaço escolar, identificando se na proposta curricular foram feitas adaptações locais necessárias para atender a população ribeirinha.

\section{PALAVRAS-CHAVE}

Comunidades Pesqueiras. Educação. Saberes Tradicionais 


\section{ABSTRACT}

Given the historical and cultural aspects that make up the individual to the social environment, is relevant to a study that enables to analyze the role of school and teacher who teaches in the program Education for Young and Adults, and in high school, to investigate if the traditional knowledge of the local population are present in the school curriculum, pedagogical and political project in school. It is essential that information about the skills and competencies of the riverside communities worked at the school involving reflection, both individually and collectively for this exercise is to allow men and women to recognize themselves as subjects of their social and cultural context, which, with such certainty, they may be able to build healthier relationships and positive environment in which they live. Before this context, is being developed a survey in order to know the school and its social actors in order to enable an understanding of what that space is limited, to integrate the knowledge of communities and analyze the complexity of knowledge women and men that build knowledge and pass on from generation to generation. Thus, we emphasized the role of adult education and high school teachers working across the region, with a view to transforming the practice of pedagogical action. Will be analyzed further, how the learning process occurs at school, identifying whether the proposed curriculum were made local adaptations necessary to meet the local population.

\section{KEYWORDS:}

Fishing Communities. Education. Traditional Knowledge.

\section{RESUMEN}

Teniendo en cuenta los aspectos históricos y culturales que integran al individuo con el entorno social, es relevante un estudio que permita analizar el papel de la escuela y el programa de formación del profesorado que imparte clases en la Educación de Jóvenes y Adultos - EJA, y en la escuela secundaria, con el fin de investigar si los conocimientos tradicionales de la población local están presentes en el currículum escolar, proyecto pedagógico y político en la escuela. Es esencial que las informaciones acerca de las habilidades y competencias de las comunidades autóctonas tratadas en la escuela envuelvan reflexión, tanto individual como colectivamente, pues es este ejercicio que permitirá que los hombres y las mujeres se reconozcan como sujetos de su contexto social y cultural, los cuales, con seguridad, podrán ser capaces de construir relaciones más sanas y positivas en el medio en que viven. Ante este contexto, se está desarrollando una investigación para conocer la escuela y sus actores sociales con el fin de permitir una comprensión de lo que limita ese espacio, contribuyendo para integrar el conocimiento de las comunidades y analizar esa complejidad de conocimiento de mujeres y hombres que construyen sabiduria y la transmiten de generación en generación. Así, se destacó el papel de la educación de adultos y los profesores de secundaria que trabajan en la región, con miras a transformar la práctica de la acción pedagógica. Se analizará también de qué forma ocurre el proceso de aprendizaje en la escuela, identificando si en la propuesta curricular se hicieron adaptaciones locales necesarias para atender a la población ribereña.

\section{PALABRAS CLAVE}

Comunidades Pesqueras. Educación. Conocimientos Tradicionales. 


\section{INTRODUÇ̃̃̃O}

$\mathrm{Na}$ contemporaneidade, percebe-se que a sociedade globalizada tenta conglomerar de uma forma homogênea valores e culturas, não deixando espaço para as singularidades de povos que têm toda uma história de saberes e vivências nas suas comunidades, uma vez que seus modos de vida diferem do modo de vida dos que residem na cidade. As comunidades que vivem ao redor do manguezal - pescadores e pescadoras - têm a riqueza desse ecossistema como fonte de vida, onde aprendem saberes para retirarem do meio ambiente a sua sobrevivência.

0 presente artigo dará continuidade à dissertação de mestrado relativa aos saberes dos homens e mulheres que vivem nas comunidades ribeirinhas de Pontal e Preguiça no município de Indiaroba, Estado de Sergipe, a qual versou acerca da história de vida das mulheres marisqueiras.

Os problemas diagnosticados na dissertação, relacionados à evasão, à reprovação e ao desinteresse pelas aulas despertaram o interesse em investigar a realidade escolar das comunidades ribeirinhas.

Diante dos aspectos históricos e culturais que integram o indivíduo ao meio social, é relevante um estudo que possibilite analisar o papel da escola e a formação do professor que leciona no programa Educação de Jovens e Adultos - EJA - Projovem Campo - Saberes da Terra, no sentido de investigar se os saberes tradicionais das populações ribeirinhas estão presentes no currículo escolar e no projeto político pedagógico da escola. É primordial que as informações sobre as habilidades e competências das comunidades ribeirinhas trabalhadas na escola envolvam reflexão, tanto individual como coletiva, pois é esse exercício que permitirá a homens e mulheres se reconhecerem como sujeitos do seu contexto social e cultural, e, com essa certeza, poderão ser capazes de construir relações mais saudáveis e positivas no am- biente em que estão inseridos. De acordo com Straus (1976), “[...] quando hábitos seculares se desmoronam, quando gêneros de vida desaparecem, quando velhas solidariedades se esboroam, é certo que uma crise de identidade se produza". Frente a esse contexto é que está sendo desenvolvida uma pesquisa com a finalidade de conhecer o espaço escolar e seus atores sociais a fim de ser possível compreender o que limita esse espaço no sentido de integrar os saberes das comunidades e analisar essa complexidade de saberes das mulheres e homens que constroem conhecimentos e os repassam de geração a geração. Para tanto, está sendo enfatizado o papel da EJA, através dos professores que trabalham na região, na perspectiva de uma prática de transformação da ação pedagógica. Analisar-se-á, ainda, de que forma ocorre o processo de aprendizagem no espaço escolar, identificando se na proposta curricular foram feitas adaptações locais necessárias para atender a população ribeirinha.

Diante do fato abordado, esta pesquisa está sendo desenvolvida no município de Indiaroba, Estado de Sergipe, envolvendo as escolas municipais que atendem as comunidades ribeirinhas das proximidades, e apresenta uma abordagem qualitativa incluindo pesquisa de campo, oficinas, o que oportunizará uma pesquisa-ação, além de entrevistas, observações nas escolas, acrescendo-se a tais modalidades, a pesquisa bibliográfica.

Para tanto, o trabalho será fundamentado através das obras de Almeida (2006), Hall (2004), Freire (1992; 2006), Charlot (2007; 2000; 2001; 2005; 2006), Shiva (2003), entre outros.

0 trabalho investigativo possibilitará um estudo acerca do papel da escola e sua relação com o saber das comunidades ribeirinhas. Saberes estes fundamentais para a valorização do indivíduo na sua formação como cidadão e sujeito da história. 


\section{POLÍTICAS PÚBLICAS E A EDUCAÇÃO DE JOVENS EADULTOS}

O Brasil apresenta um grande desafio que é justamente erradicar o analfabetismo, uma vez que as pesquisas realizadas por diversos órgãos constataram que no Brasil ainda há um grande índice de analfabetos, principalmente na região Nordeste, onde ainda prevalece a questão de gênero: a mulher em relação ao homem. Diante desse quadro, a pesquisa envolve as comunidades pesqueiras em que os sujeitos (homens e mulheres) trabalham desde a infância acompanhando os pais na pesca, até a fase da adolescência quando começa o abandono do espaço escolar devido tanto à falta de tempo quanto à necessidade econômica da sobrevivência. Para sobreviverem, homens e mulheres enfrentam os manguezais e o mar onde ficam oito horas por dia, e quando chegam continuam o trabatho de armazenar os pescados.

\section{De acordo com os dados da Unesco:}

Nos dez anos seguintes, um comitê de organismos da ONU, liderados pela Unesco, concentrou a ajuda internacional em nove países populosos com índices elevados de analfabetismo, rol em que o Brasil aparece ao lado de Bangladesh, China, Egito, Índia, Indonésia, México, Nigéria e Paquistão. Admitindo que as metas de Educação para Todos não haviam sido alcançadas, a avaliação realizada em 2000 - no Fórum Mundial de Educação realizado em Dacar -, no Senegal, postergou para 2015 a consecução dos seis objetivos prioritários, entre os quais a redução, à metade, dos índices de analfabetismo, com igualdade de oportunidades para as mulheres e acesso equitativo de todos os adultos à educação básica e continuada (UNESCO, p. 26).

A Educação de Jovens e Adultos é destinada às pessoas que no período normal não conseguiram avançar nos seus estudos e foi concebida com a finalidade de nela incluir a população brasileira sem escolaridade. Porém, mesmo com o Programa, ainda persiste um índice relevante de analfabetismo. Assim, cabe ao governo investir em Políticas Públicas que possam atender com propostas inovadoras aos anseios da comunidade, observando o que leva essas pessoas a abandonarem o estudo e, por consequência, desco- brir estratégias que as levem ao retorno à escola. $\mathrm{Na}$ pesquisa, através dos depoimentos das marisqueiras, elas afirmam que não têm cabeça para estudar. Através da observação in loco, foi possível constatar que elas desenvolvem várias atividades durante o dia, sem qualquer ajuda. Elas fazem todo o trabalho começando pela pesca, a quebra do aratu, a venda do produto, a organização do orçamento familiar através da venda e outras atividades, como juntar palhas de coqueiro nos sítios quando não vão à maré, catar mangabas para vender na feira, e, ao mesmo tempo cuidam dos filhos, marido e da casa.

Assim, a pesquisa foi iniciada envolvendo o contexto escolar, com o objetivo de avaliar a proposta pedagógica do Programa Projovem do Campo - Saberes da Terra, que tem como meta alfabetizar e profissionalizar os estudantes do campo, através de uma proposta de integração dos saberes formais aos saberes da academia, os quais devem estar articulados através de eixos temáticos. 0 programa tem duração de dois anos quando o estudante conclui o ensino fundamental e é preparado para a agricultura familiar, ao tempo em que se torna apto a ingressar em curso de formação do nível médio ou técnico profissionalizante.

Através da pesquisa desenvolvida será possível analisar por meio das observações e entrevistas com professores, coordenadores e alunos a proposta pedagógica do programa, a formação do professor que leciona e as possíveis dificuldades com o programa em relação aos alunos. Na pesquisa observam-se algumas queixas dos alunos em relação ao professor.

\footnotetext{
Os professores não são da comunidade e chegam tarde para começar as aulas, não conhecem nossa realidade e os assuntos são os mesmos. Queremos avançar, mas não temos, na comunidade, a continuidade do programa, apenas o Brasil Alfabetizado e o assunto são os mesmos se quisermos fazer de novo. O certo era ter
} 
outro programa, para a gente terminar o ensino fundamental e viajar para a sede. Fica muito cansativo. (ALUNA X, 2011)

Assim, observa-se que, mesmo com um programa o qual procura articular os textos à realidade do aluno, faltam ainda políticas públicas que invistam na própria comunidade, e estimulem o processo de aprendizagem utilizando estratégias de

\section{PLANEJAMENTO E DESENVOLVIMENTO DAS COMPETÊNCIAS: DESAFIOS PARA A PRÁXIS DOCENTE}

Toda ação requer planejar para obter resultados satisfatórios, ou mesmo descobrir erros a partir dos obstáculos enfrentados. 0 planejamento orienta 0 trabalho pedagógico do professor e estimula a produção de ações estratégicas dirigidas para o perfil da turma, ou seja, o ambiente social em que estão inseridos. A partir do planejamento, o professor cria o hábito de pesquisar com vistas a ofertar aos seus alunos um ambiente agradável de afetividade, compartilhamento e aprendizagem.

Considerando o observado no parágrafo anterior, constata-se que a aprendizagem só ocorre quando o educador percebe o aluno na sua complexidade, ou seja, como um ser em construção que tem uma bagagem cultural e sofre influência social do meio em que vive. Diante dessas observações, cabe ao professor refletir quanto à sua práxis pedagógica, criar ações que estimulem saberes, reduzam a evasão escolar e proporcionem um ambiente de saberes compartilhados.

A relação entre o professor e o aluno depende da formação do primeiro e do contexto de vida do segundo. Para o primeiro, a preparação para o exercício do magistério em qualquer nível precisará ir além da simples interiorização e apropriação de conteúdos programáticos relativos a determinadas situações complexas que ensino que possibilitem avançar no seu processo de formação. A alfabetização de adultos perpassa por princípios de valorização do sujeito como agente de transformação, e cabe ao professor despertar o desejo do aprender agindo como mediador; para que isso aconteça, é preciso que ele tenha uma boa formação a fim de ser possível notar as dificuldades e avançar no enfrentamento das necessidades dos alunos.

\begin{abstract}
serão abordadas no processo de ensino. A formação do professor deverá permitir-lhe desenvolver uma ampla visão e compreensão do estudante como o "aprendente”, ou seja, aquele que constrói seu próprio conhecimento. Esta construção não está restrita apenas ao campo cognitivo do sujeito, mas depende também de suas características de temperamento e personalidade. Se cada sujeito é diferente na sua maneira de ser e de agir, ele o será também em sua maneira de aprender. Assim, o planejamento de ações pedagógicas deve levar em conta essas singularidades de aprendente, da mesma forma que leva em conta a opção pelo modelo pedagógico para o ensino (MORETTO, 2010, p. 13).
\end{abstract}

O ensinar envolve momentos de reflexão e análise para compreender o perfil do educando e pensar estratégias que avancem tanto no sentido da construção do conhecimento, como também da sua formação como sujeito que precisa saber conviver e compartilhar numa sociedade ainda individualista, competitiva e preconceituosa. É preciso respeitar suas diferenças, não para afastar, mas sim agregar, estimular e levantar sua autoestima proporcionando-lhes condições de avançar quando estimulados. De acordo com os depoimentos das marisqueiras, o motivo de não estudarem é o cansaço da lida na pesca do aratu, mas, além disso, as atividades na escola são muito difíceis e elas não conseguem compreender. 
Para Moretto (2010), o ensinar tem o significado de apresentar aos estudantes as representações construídas, para que eles, individualmente e em grupo, se apropriem significativamente dos objetos de conhecimentos e, com isso, sejam inseridos nos saberes construídos por seu grupo social.

O ensinar, nessa perspectiva, proporciona compreender a complexidade do sujeito inserido na sociedade, estimula o processo cognitivo e criativo, devido a representar o contexto social e a valorizar o conhecimento que os alunos trazem consigo, proporcionando uma troca de saber. Cabe, então, propiciar vários tipos de ações pedagógicas que estimulem o processo de aprendizagem. No decorrer da pesquisa, percebeu-se que existem na sala de aula alunos de variadas etapas de conhecimento: os que já estão conseguindo decifrar os códigos para a introdução da leitura, os que identificam apenas as letras, e aqueles que estão no início do processo de assimilação do conhecimento.

Percebe-se, então, que existe a necessidade de o professor compreender todo esse contexto, a fim de possibilitar que o aluno não se sinta desestimulado e não perceba a escola como um local estranho do seu contexto social. É compreensível que nas atividades os alunos que estão em um contexto diferenciado no seu processo de aprender apresentam uma vontade de dominar os códigos da escrita para entender os textos. No decorrer da pesquisa, foi constatado que alguns professores do Programa de Educação de Jovens e Adultos não moram na comunidade e não conhecem a realidade do contexto social dos alunos do programa. Outros são da comunidade, mas têm dificuldade de utilizar uma metodologia que possa estimular a vontade do querer aprender, faltam-lhes habilidades em ações pedagógicas que possibilitem ao aluno avançar.

Na perspectiva do planejamento, cabe ao professor observar o nível de conhecimento do aluno, os conteúdos programáticos do currículo, o contexto so- cial dos pescadores que estão em sala de aula, com a finalidade de integrar ações pedagógicas que proporcionem analisar, refletir, decodificar e assimilar o aprendido em várias situações que podem surgir no decorrer das aulas. Como já foi afirmado, alunos que têm bom acompanhamento dos professores - que detectam as dificuldades apresentadas na leitura e na matemática - avançam mais rápido no seu processo de aprendizagem, ao contrário do que acontece com alunos que não têm esse acompanhamento e sentem mais dificuldade, perdendo o desejo de aprender como já ficou constatado, caso o professor não tenha estratégias de desenvolvimento. Na escola pesquisada, observou-se um espaço adequado, material permanente em boas condições, porém há uma falta de recursos didáticos, ou eles são precários, fator este que interfere no trabalho do professor.

Muitas vezes os professores ficam desestimulados para exercer a profissão, justamente pelas dificuldades encontradas que envolvem desde a falta de recurso didático, a ausência de um suporte pedagógico que possa fazer um trabalho integrado, além da falta de investimento na sua formação continuada.

A sociedade capitalista cria um sistema econômico que proporciona uma divisão no espaço escolar, formando uma dualidade no sistema de ensino. A escola pública está melhorando, mas ainda precisa muito de políticas públicas que verdadeiramente possam cumprir sua função de oportunizar uma educação de qualidade para todos.

No decorrer da pesquisa observou-se que existem pescadores envolvidos com o álcool, principalmente os homens, como também adolescentes grávidas e jovens mães, porém algumas escolas permitem que o filho pequeno acompanhe a mãe, mas algo sem muita estrutura. Às vezes o pessoal de apoio fica com as crianças. Tudo ainda muito precário.

Diante dos fatos apresentados, é fundamental um planejamento flexível que crie oportunidades 
de ampliar o conhecimento do aluno através de atividades que despertem o desejo e proporcionem espaço para afetividade e possam auxiliar o outro. Observou-se, ainda, que a implantação do projeto Projovem do Campo tenta, justamente, relacionar os saberes do contexto social dos alunos aos saberes formais das diretrizes curriculares da Educação de Jovens e Adultos; isto ainda não é uma rotina, mas notaram-se mudanças em alguns comportamentos. 0 altruísmo prevalecendo em relação ao egoísmo leva o sujeito a saber conviver em grupo, saber viver na coletividade e estimular o respeito ao próximo e ao meio ambiente, ou seja, educar para a solidariedade.

\section{CONSIDERACÕ̃ES FINAIS}

O Programa de Educação de Jovens e Adultos, segundo consta na proposta curricular, procura oportunizar aos alunos não alfabetizados, ou mesmo o alfabeto funcional, avançar nos estudos, além de contribuir de maneira eficaz para o aperfeiçoamento das práticas educativas com jovens e adultos. Mesmo sendo um referencial, percebe-se, nas pesquisas em andamento, uma grande dificuldade de avançar no processo de aprendizagem das comunidades pesqueiras, principalmente da população de homens e mulheres com 30 anos de idade em diante, até mesmo com as jovens que deixam os estudos devido à gravidez precoce, como também seus parceiros que precisam trabalhar para manter a família. Além disso, as atividades da pesca sofrem alterações da ida ao mar devido às mudanças da maré, fazendo com que tanto os pescadores quanto as marisqueiras fiquem à espera do melhor momento para pescar. Assim, percebe-se um dos entraves

que os afastam do ambiente escolar devido à carga horária que passam na pesca.

Os programas escolares não sofrem adaptação de horário devido aos horários dos professores que lecionam na comunidade; outro fato observado é que alguns professores são de outras comunidades e não têm uma formação contextualizada da comunidade onde lecionam e alguns sentem dificuldade de utilizar outras estratégias didáticas para melhor conhecimento do aluno.

A pesquisa está em andamento, e, além das rodas de conversas com professores, alunos, pescadores e marisqueiras da região, vão ser iniciadas oficinas com temáticas contextualizadas estimulando a formação continuada e ao mesmo tempo colhendo dados sobre a formação do professor que leciona no programa EJA nas comunidades pesqueiras. 


\section{REFERÊNCIAS}

ALMEIDA, Maria da Conceição; PEREIRA, Wani Fernandes. Lagoa do Piató: fragmentos de uma história. 2. ed. Natal: Editora da UFRN, 2006.

BRASIL Constituição da República Federativa do Brasil. Brasília, 05 de outubro de 1988. Disponível em: <www.planalto.gov.br.> Acesso em: 30 set 2010.

CHARLOT, Bernard. Da relação com o saber: elementos para uma teoria. Tradução por. Bruno Magne. Porto Alegre: Artmed, 2000.

CHARLOT, Bernard. Os jovens e o saber: perspectivas mundiais. Tradução por Fátima Murad. Porto Alegre: Artmed, 2001.

CHARLOT, Bernard. Relação com o saber, formação dos professores e globalização: questões para a educação hoje. Porto Alegre: Artmed, 2005.

CHARLOT, Bernard. Jovens de Sergipe: quem são eles, como vivem, o que pensam. Aracaju: Futuras Gráfica \& Serviços Ltda., 2006.

DANTAS, Vanda Maria Campos Salmeron. Nas marés da vida: histórias e saberes das mulheres marisqueiras. Dissertação (Mestrado em Ciências Sociais), 2010. Universidade Federal do Rio Grande do Norte, Natal, 2010.
FREIRE, Paulo. Pedagogia da esperança: um reencontro com a pedagogia do oprimido. Rio de Janeiro: Paz e Terra, 1992.

FREIRE, Paulo. Pedagogia da autonomia: saberes necessários à prática educativa. São Paulo: editora Paz e Terra, 2006.

HALL, Stuart. A Identidade cultural na pós-modernidade. Trad. Tomaz Tadeu e Guacira Louro. Rio de Janeiro: Editora DP\&A, 2004.

LÉVI - STRAUSS, Claude. 0 pensamento selvagem. São Paulo: Nacional, 1976.

MORETTO, Vasco Pedro. Planejamento: planejando a educação para o desenvolvimento de competências. Petrópolis - RJ: Vozes, 2010.

ORGANIZAÇÃO DAS NAÇÕES UNIDAS PARA A EDUCAÇÃO, A CIÊNCIA E A CULTURA - UNESCO. Alfabetização de jovens e adultos no Brasil: lições da prática. Brasília: UNESCO no Brasil, 2008.

SHIVA, Vandana. Monoculturas da mente: perspectivas da biodiversidade e da biotecnologia. Tradução por Dinah de Abreu Azevedo. São Paulo: Gaia, 2003. 